\title{
Sex hormones abnormalities in non-alcoholic fatty liver disease: pathophysiological and clinical implications
}

\author{
Angelo Di Vincenzo $^{1 *}$, Lucia Russo $^{2}$, Carlo Giovanni Doroldi ${ }^{1}$, Roberto Vettor $^{2}$, Marco Rossato $^{2}$ \\ ${ }^{1}$ Internal Medicine Unit, Camposampiero Hospital, 35012 Camposampiero, Italy \\ ${ }^{2}$ Department of Medicine, University-Hospital of Padova, 35121 Padova, Italy
}

*Correspondence: Angelo Di Vincenzo, Camposampiero Hospital, 35012 Camposampiero, Italy. divincenzoang@gmail.com Academic Editor: Amedeo Lonardo, Azienda Ospedaliero-Universitaria di Modena, Italy

Received: January 4, 2021 Accepted: May 25, 2021 Published: August 31, 2021

Cite this article: Di Vincenzo A, Russo L, Doroldi CG, Vettor R, Rossato M. Sex hormones abnormalities in non-alcoholic fatty liver disease: pathophysiological and clinical implications. Explor Med. 2021;2:311-23. https://doi.org/10.37349/ emed.2021.00049

\begin{abstract}
Obesity and metabolic syndrome are conditions at high risk for the development of complications such as type 2 diabetes mellitus, atherosclerotic cardiovascular disease, and non-alcoholic fatty liver disease (NAFLD). The growing prevalence of NAFLD has recently raised attention in the clinical practice, due to the worsening prognosis observed in the affected patients. Sex hormones abnormalities, commonly found in subjects suffering from obesity and metabolic syndrome, have been recently hypothesized to be directly involved in the physiopathology of obesity-related comorbidites; however, their role in the pathogenesis of NAFLD remains unclear. In this review of the available literature, a summary of the knowledge about the role of sex steroids abnormalities in the risk of developing NAFLD was performed, mentioning the possible clinical implications for therapy.
\end{abstract}

\section{Keywords}

Non-alcoholic fatty liver disease, sex hormones, testosterone, obesity, metabolism

\section{Introduction}

As non-alcoholic fatty liver disease (NAFLD) reached worldwide diffusion, emerging as the most frequent chronic liver disorder, great efforts have been made in both clinical and pre-clinical research areas with the aim to identify strategies to treat and prevent this condition. However, the physiopathology of NAFLD remains an unresolved topic, with still limited therapeutic approaches in the clinical practice. Considering that metabolic syndrome (MetS), obesity and type 2 diabetes mellitus (T2DM) remain the most relevant risk factors for the development and progression of liver damage [1], the treatment of NAFLD usually overlaps the management of these concomitant conditions. However, the interconnection is even more complex, considering that the relationship between MetS and NAFLD seems bidirectional, with the presence of NAFLD increasing the probability of being diagnosed with T2DM or MetS [2], and recently, it has been demonstrated that the presence of NAFLD anticipates the development of T2DM and even arterial hypertension, and this 
seem related with the severity of liver fibrosis [3]. Despite several antidiabetic drugs have been proven effective in the amelioration of clinical and even histological parameters of NAFLD [4, 5], the lifestyle modifications including diet and exercise aiming to weight reduction and weight loss maintenance remain the cornerstone for the treatment of NAFLD [6]. Recently, also bariatric surgery emerged as a potential therapeutical approach for NAFLD [7], despite its indication remains limited to severe obesity or less severe obesity (body mass index $\geq 35 \mathrm{~kg} / \mathrm{m}^{2}$ or even body mass index $\geq 30 \mathrm{~kg} / \mathrm{m}^{2}$ ) associated to complication such as T2DM [8]. Obesity and MetS not only lead to the development of metabolic liver disorders, but are also characterized by a constellation of endocrine and hormonal disturbances further affecting the quality of life of patients. In this sense, the abnormalities of the reproductive function are extremely relevant. The hormonal alterations usually observed in obesity and MetS are represented by male obesity-secondary hypogonadism (MOSH), and polycystic ovary syndrome (PCOS). Accumulating evidence is showing how these endocrine disturbances contribute not only to the maintenance of the excess body weight, but even aggravate the progression of metabolic and vascular complications related with obesity $[9,10]$.

In fact, in obesity the development of NAFLD results from the metabolic derangements occurring in the expanded adipose tissue and promoting both insulin resistance and inflammatory processes, which are key factors in the physiopathology of NAFLD [11]; however, these metabolic flaws seem also involved in the development of hypothalamic-gonadal axis abnormalities affecting patients with MetS and/or obesity. In this sense, in the light of the gender differences observed in the epidemiology of liver diseases, the role sex hormones in the development and progression of NAFLD has been hypothesized. In fact, epidemiological studies have shown a higher severity of the disease in men than in women, suggesting a detrimental effect of androgens and, on the contrary, a protective effect of estrogen in the pathogenesis of NAFLD. We provided a brief summary of the available evidence supporting a plausible role of sex steroids in NAFLD pathophysiology, mentioning the possible therapeutic implications in patients with liver disease.

\section{Androgens and estrogens in the epidemiology of liver diseases and NAFLD}

NAFLD is characterized by progressive liver abnormalities, starting from an increased intra-hepatic adipose tissue deposition defined as steatosis or fatty liver, to more severe histological damage represented by steatohepatitis [non alcoholic steatohepatitis (NASH)] and fibrosis. These alterations lead to hepatic and extra-hepatic complications if an adequate treatment is not proposed, and in this sense the spreading diffusion of NAFLD, along with the associated high mortality, poses relevant questions for the public health systems. NAFLD is in fact associated with an increased risk of cirrhosis and hepatocellular carcinoma (HCC), now representing the main indication to liver transplantation worldwide [12]. However, besides the wellestablished liver-related disability, NAFLD has been recently associated with an increased cardiovascular morbidity and mortality [13].

As for other human diseases, a gender-related epidemiology can be observed also for NAFLD, with sex differences modulating different prognosis and severity. It is well known that autoimmune liver diseases are more frequent in female while, on the contrary, male has a higher incidence of liver cancer. With this regard, a role for sex hormones in the carcinogenesis and progression of HCC has been proposed [14]. As observed in preclinical studies involving androgen receptor (AR) knockout animal models, the inhibition of AR pathway is characterized by slowing progression of HCC; on the contrary, as observed in $N^{\prime}, N^{\prime}$-diethylnitrosamine (DEN)induced HCC models, estrogens exert a protective role on neoplastic transformation [15]. So, androgen and estrogen receptor pathways could modulate carcinogenesis in a different manner [16], resulting in a different sex-derived risk.

As for HCC, also the prevalence of NAFLD is higher in men than in women, and in fact male sex has been traditionally considered as a risk factor for of NAFLD [17], despite the management of NAFLD and associated risk factors in the female can be very tricky [18]. It is interesting to note that this difference becomes less pronounced with aging: in particular, while the prevalence in pre-menopausal women is about $6 \%$, an increased risk for developing NAFLD is observed in female after menopause, with rate of disease prevalence similar to those of men [19]. Age represents an independent factor for the development of NAFLD, probably 
due to the increasing prevalence of the features of MetS occurring in both sexes during aging; however, the hormonal modification occurring in the elderly and, in the female, in the post-menopausal period, may further explain these epidemiological aspects. The increased risk for NAFLD in post-menopausal women can be easily referred to the drop of circulating estrogens [20], while in the male the age-related hormonal abnormalities can explain the development and progression of NAFLD. Similar to obese male subjects, in the aging male a reduction of testosterone plasma levels is usually observed, a condition also defined as andropause. Accumulating evidence has shown how hypogonadism can contribute to the development of several cardiovascular and metabolic conditions, and recent studies are suggesting that low testosterone plasma levels in the male are associated with the development of NAFLD and the progression of liver steatosis to NASH, even at younger age. So, according to these epidemiological data, a role for hormonal abnormalities in the physiopathology and the natural history of NAFLD is strongly plausible.

Recently, the definition of new risk factors for the development and/or progression of NAFLD raised attention in medical practice. Clinical observation proposed the role of gender in the physiopathology of NAFLD. The complex role of androgens and estrogen in lipid and glucose metabolism have been proposed, such as their modulation of inflammatory responses and then even of fibrotic process [21]. Subsequently, evidence has grown up about the epidemiological relationship between NAFLD risk and sex status, with sex emerging as a main risk disease modifier [22]. However, only few clinical studies were performed aiming to clarify the influence of sex on NAFLD pathogenesis, progression and even therapeutic responses $[23,24]$.

\section{Relationship between NAFLD and sex hormones abnormalitiese}

The risk of developing NAFLD is associated with the presence of metabolic abnormalities such as MetS and both polygenic and monogenic obesity syndromes. These conditions are characterized by a state of insulin resistance related to a dysfunctional adipose tissue: the systemic complications of obesity and MetS are consequent not only to the excessive expansion of fat depots, but even more with adipose tissue distribution and function [25]. In fact, the visceral adipose tissue (VAT) is the fat depot characterized by the higher metabolic activity and, when reaching the maximum adipocytes expansion due to an excessive energy intake, it becomes dysfunctional, with an abnormal production of adipokines and pro-inflammatory cytokines and consequent local recruitment of inflammatory cells [11].

As mentioned above, metabolic disturbances are also associated with hormonal abnormalities. In the male, obesity, MetS and T2DM are associated with subnormal or low testosterone and higher estradiol plasma levels, while women with obesity and MetS commonly develop PCOS. Despite the fact that different clinical and biochemical phenotypes exist, sometimes not showing biochemical (and/or clinical) hyperandrogenism [26], PCOS is often characterized by increased circulating levels of androgens. Hypogonadism in the male and hyperandrogenism in the female have been recently considered as independently associated with an increased risk for developing NAFLD. This represents a relevant point, considering not the epidemics of obesity, but also recent data showing a higher prevalence of severe obesity in women than in men (age-adjusted prevalence $11.5 \%$ vs. 6.9\%) [27, 28]. However, how these sex hormone abnormalities could promote liver damage remains unclear. This is probably consequent to the indirect effects of sex hormones on energy homeostasis, due to their action on the metabolism of adipocytes, pancreatic $\beta$-cells and even hepatocytes. It is well known that testosterone is involved in adipose tissue biology, promoting different cellular and biochemical responses through the interaction with the AR. In particular, testosterone prevents the adipose accumulation promoting a myogenic commitment of pluripotent mesenchymal cell and inhibiting adipogenic differentiation [29]. Furthermore, testosterone may preserve pancreatic function protecting pancreatic $\beta$-cells from glucotoxicity, and promote an increase of lean mass with overall benefits on insulin sensitivity. These positive effects seem to fade when testosterone plasma levels are reduced; thus, when MOSH is established, the obesity status is maintained with a concomitant increased risk of metabolic diseases such as T2DM and even NAFLD. Both cross-sectional and longitudinal studies have shown that low testosterone plasma levels are independently associated with the features of MetS, while other studies have even shown a 
correlation between testosterone plasma levels and obesity-related complication, with low testosterone levels predicting the development of T2DM in men [30]. Other observational studies demonstrated an association between low androgens levels and the risk of NAFLD; in particular, in a cross-sectional study involving 1,912 men, lower levels of testosterone and dehydroepiandrosterone sulphate (DHEAS) were associated with sonographic-diagnosed hepatic steatosis, with age not significantly affecting this association [31]. This association was recently confirmed also in histologically-proven NAFLD [32], and very interestingly, reduced serum concentration of testosterone was demonstrated to be independently related with a more severe histological pattern of liver disease [33]. So, as already demonstrated in T2DM, male hypogonadism can represent a risk factor also for NAFLD, and its treatment could be beneficial in patients with MetS/obesity to prevent the development of NAFLD.

The complexity of this sex hormone-liver axis in NAFLD can be further described observing the different role of androgen between sexes: in fact, while low testosterone plasma levels are associated with NAFLD in men and even in post-menopausal women [34], on the contrary, in pre-menopausal women, the risk of developing NAFLD increases with increasing testosterone plasma levels [35]. This became evident in women with PCOS, who present a higher risk of NAFLD respect to age- and adiposity-matched controls, with the androgen excess (in particular serum testosterone levels higher than $3.0 \mathrm{nmol} / \mathrm{L}$ ) strictly associated with NAFLD [hazard ratio (HR) $=2.30,95 \%$ confidence interval (CI) 1.16-4.53, $P=0.017$ ] [36]; in fact, in subjects with PCOS, sex hormones abnormalities seem to be independently associated with higher risk of fibrosis progression [37], thus PCOS has been recognized as a risk factor for the development of NAFLD, [17]. Then androgen levels seem to modulate the development of NAFLD in a sex-dependent manner, with hypogonadism being a risk factor in the male while, conversely, hyperandrogenism is in the female (Figure 1). In this sense, male patients with hypogonadism and female suffering from PCOS (with increased androgens levels) should be appropriately screened for NAFLD in clinical practice.

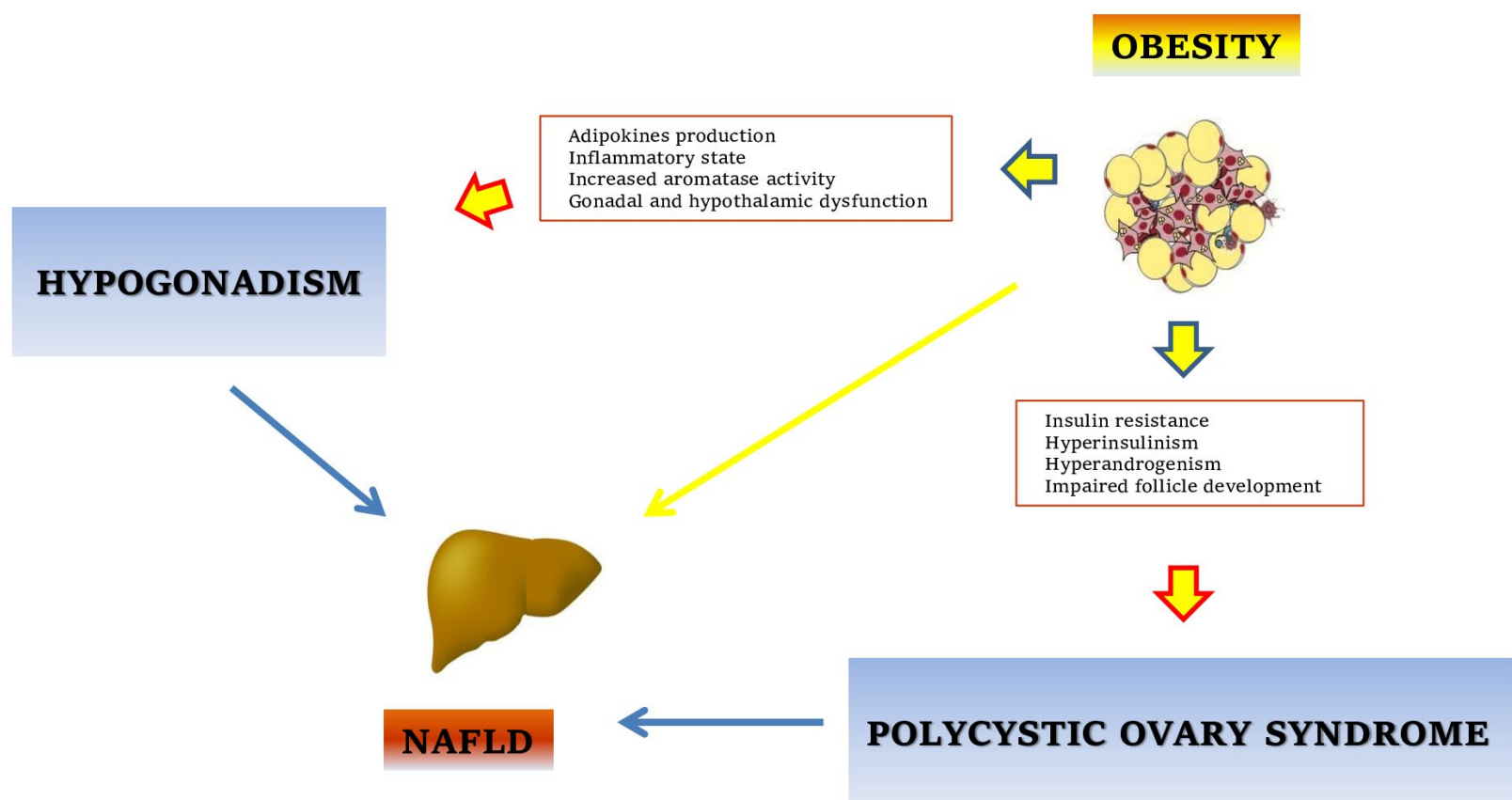

Figure 1. Relationship between obesity, reproductive function abnormalities and NAFLD

However, itshould be kept in mind that the different techniques used for the measurement of sex hormones levels may result in different and are not always reliable data from the studies. In fact, circulating androgens plasma levels are usually measured by direct and indirect immunoassay methods [38]; however, direct immunoassays are seldom thoroughly validated and often lack sensitivity and specificity [39]. In addition, in the female, the detection of androgens can be very tricky, considering that existing assays required large amounts of serum, and that measurement of androgens may reflect reservoir of precursor substrates for estrogens. Liquid chromatography-tandem mass spectrometry is touted to become the "gold standard" for all 
steroid hormone measurements, but despite a growing use of assays that combine mass spectrometry with either gas or liquid chromatography for quantifying androgens, it is available only in few centers. However, it showed a higher precision, sensitivity, and accuracy for measuring androgen levels in the female [40]. Most of the cited studies did not report the same methods for the determination of sex hormones plasma levels (and sometimes did not report any method), and this heterogeneity may represent a relevant bias in the definition of the relationship between hormonal abnormalities and NAFLD. The situation became even more complex considering that also the diagnosis of NAFLD may be biased (ultrasound, liver function tests, and biopsy).

\section{Sex hormones modulation of liver metabolism}

A sexual dimorphism can be observed in the liver related not only to drug metabolism but also to lipogenesis, glucose metabolism, oxidative stress and even fibrosis [41, 42]. Steroid hormones (both glucocorticoids and androgens) are regulators of metabolic phenotype, and are involved in hepatic lipid accumulation and glucose metabolism [43-47]. Sex hormones modulate both genomic responses, through the interaction with nuclear receptors, and also non-genomic responses, activating signaling cascade through cell surface receptors. Genomic pathways are characterized by higher latency, while membrane interaction (nongenomic) is characterized by rapid responses. Sex steroids hormones are produced by gonads and adrenals, but sex hormones plasma levels are influenced also by peripheral conversion of circulating steroids, and the peripheral tissues involved in the conversion of sex hormones are mainly represented by the adipose tissue and the liver [48]. Androgens and estrogen are present in different concentrations in both sexes. As reported above, androgen deficiency in men and androgen excess in women are risk factor for NAFLD development and progression, while a protective effect is observed with estrogens [49]. The complex interplay between reproductive axis and metabolic diseases has been defined in the setting of metabolic disturbances, and a different role of androgens among sexes is becoming evident, with low testosterone levels associated with increased risk of NAFLD in men but not in women [35]. Furthermore, as recently observed, increased free testosterone levels are associated with an increased prevalence of NAFLD in adult women [50], suggesting a pathophysiological basis for the risk of liver disease in post-menopausal subjects. In men, lower testosterone levels are even associated with higher disease severity expressed by the fibrosis-4 (FIB-4) index [51]. The relationship between sex hormones and liver is probably a two-way pathway, with the liver involved in the peripheral conversion of steroids, and sex steroids modulating liver physiology due to the androgen and estrogen receptor expression on hepatocytes surface [52]. Thus, the liver is both source and target of the hormonal signals.

The gender-related differences in liver diseases an NAFLD between sexes could be, at least partially explained with the different role and expression of steroids receptors among sexes [53-55]. As above mentioned, AR pathway activation is recognized as a relevant mechanism in the physiopathology of HCC. Li et al. [56] observed that AR knocking-out of K-ras transgenic zebrafish reduced the risk of developing HCC; anyway, they also observed that androgen treatment promoted tumor progression in knock-out models but not in wild-type animals, suggesting a pro-oncogenic effect of androgen AR-independent for androgens. Estrogen receptors (ERs) are highly expressed in the liver in females because this pathway is involved in the metabolic fluctuation occurring during the reproductive age, pregnancy, and lactation: in fact, sex hormones modulate metabolic responses to the different nutritional requests which female mammals are exposed during fertile age through the interaction with ER [57]. However, the ER pathway activation seems to present beneficial effects even in the male, as observed in animal models of obesity in which ER $\alpha$ knock-out was associated with reduced hepatic insulin sensitivity, suggesting a direct involvement of ER $\alpha$ signaling in the development of NAFLD [58], above all the indirect metabolic effects such as the adipose tissue expansion [59]. A summary of the above mentioned findings is reported in Table 1. 
Table 1. Summary of findings about the role of sex hormones in the risk of NAFLD

\begin{tabular}{l}
\hline Sex hormones, metabolism, and the risk of developing NAFLD \\
\hline -In the male the risk of NAFLD is higher than women \\
-In the male low androgens levels may increase the risk of NAFLD \\
-In the male with obesity/MetS, low androgens levels are frequently observed and are associated with the presence of NAFLD \\
-In the female with obesity/MetS, the presence of PCOS may increase the risk of NAFLD \\
-In the female, during the pre-menopausal period, the risk of NAFLD is lesser than men \\
-In the female, during the post-menopausal period, the risk of NAFLD is similar to men \\
-Both men with low androgen levels and women with PCOS should be screened for NAFLD
\end{tabular}

The peculiar enzymatic activity of the liver could further explain the sex differences in NAFLD

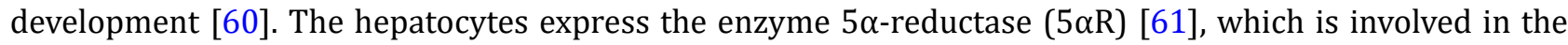
conversion of circulating testosterone to dihydrotestosterone (DHT). This enzyme is largely expressed in the reproductive tract and prostate, with two isoforms that have been identified: $5 \alpha$-reductase type 1 ( $5 \alpha \mathrm{R} 1$ ) is present in most tissues in the body, and $5 \alpha$-reductase type $2(5 \alpha \mathrm{R} 2)$ which is the prevalent isoenzyme expressed in the reproductive tract and prostate. The rationale for the clinical use of $5 \alpha$-reductase inhibitors such as finasteride in the setting of benign prostate hypertrophy relies on the reduction of locally active DHT, the most active physiological androgen. However, this enzyme seems involved also in the regulation of some metabolic pathways in the liver, as reported from several basic studies. It has been previously demonstrated that $5 \alpha$ R1-knock-out high fat-fed mice are more prone to develop hepatic steatosis and fibrosis with respect to wild-type mice, and similar results have been observed also in Zucker rats treated with finasteride [62], suggesting a negative metabolic effect of $5 \alpha \mathrm{R}$ inhibitors on liver steatosis. This is in line with results coming from clinical studies showing that the dual inhibition of both $5 \alpha \mathrm{R} 1$ and $5 \alpha \mathrm{R} 2$ obtained with dutasteride was associated with a reduction of insulin sensitivity [63]. Subsequently, it was demonstrated that the blockade of both $5 \alpha \mathrm{R}$ isoforms is associated with an increased intra-hepatic fat deposition as observed with magnetic resonance spectroscopy [64]. How the $5 \alpha \mathrm{R}$ pathway could affect the metabolic activity of the liver metabolism is not clearly understood yet. The most probable hypothesis is that that $5 \alpha \mathrm{R}$ indirectly affects the lipogenesis on hepatocytes, modulating the concentration of androgens and glucocorticoids at pre-receptor level [65]. However, as our knowledge expands, new theories are coming. Recently, a new enzymatic activity has been observed influences the development of NAFLD, as reported from Nikolau et al. [66], who described the role of steroid $5 \beta$-reductase, also known as AKR1D1, in the progression and severity of NAFLD. A summary of the studies suggesting the relationship between sex hormones and the risk of NAFLD is reported in Table 2 .

Table 2. Summary of the studies evaluating the role of sex hormones in the risk of NAFLD

\begin{tabular}{|c|c|c|c|}
\hline References & Type of study & Population & Findings \\
\hline Völzke et al. [31] & Observational & $\begin{array}{l}\text { Adult men recruited from the } \\
\text { SHIP study }\end{array}$ & $\begin{array}{l}\text { Hepatic steatosis is associated with low } \\
\text { testosterone and high DHEAS levels }\end{array}$ \\
\hline Van de Velde et al. [32] & Observational & $\begin{array}{l}\text { Adult men with obesity } \\
\text { scheduled for bariatric surgery } \\
\text { undergoing liver biopsy }\end{array}$ & $\begin{array}{l}\text { Subjects with NASH have lower cFT levels and a } \\
\text { higher cFE2/cFT ratio as compared to those with } \\
\text { only fatty liver }\end{array}$ \\
\hline Sarkar et al. [33] & Observational & $\begin{array}{l}\text { Adult men with biopsy-proven } \\
\text { NAFLD }\end{array}$ & $\begin{array}{l}\text { Men with low free testosterone are more likely to } \\
\text { have NASH and advanced fibrosis }\end{array}$ \\
\hline Yim et al. [34] & Observational & $\begin{array}{l}\text { Adult subjects participants from } \\
\text { the NHANES 2011-2012 }\end{array}$ & $\begin{array}{l}\text { Low total testosterone levels were associated } \\
\text { with abnormal ALT levels in men and post- } \\
\text { menopausal women irrespective of other risk } \\
\text { factors }\end{array}$ \\
\hline Kumarendran et al. [36] & Observational & $\begin{array}{l}\text { Women aged } 18-50 \text { with and } \\
\text { without PCOS }\end{array}$ & $\begin{array}{l}\text { Patients with PCOS have an increased rate of } \\
\text { NAFLD irrespective of BMI or impaired glucose } \\
\text { metabolism }\end{array}$ \\
\hline Sarkar et al. [37] & Observational & $\begin{array}{l}\text { Women aged } 18-45 \text { years with } \\
\text { and without PCOS and biopsy- } \\
\text { confirmed NAFLD }\end{array}$ & $\begin{array}{l}\text { The presence of PCOS was associated with an } \\
\text { increasing fibrosis in patients with NASH }\end{array}$ \\
\hline Sarkar et al. [50] & Observational & $\begin{array}{l}\text { Healthy Caucasian and African } \\
\text { American women aged } 18-30\end{array}$ & $\begin{array}{l}\text { Increased free testosterone levels are associated } \\
\text { with NAFLD independently from BMI, insulin } \\
\text { resistance and waist }\end{array}$ \\
\hline
\end{tabular}


Table 2. Summary of the studies evaluating the role of sex hormones in the risk of NAFLD (continued)

\begin{tabular}{|c|c|c|c|}
\hline References & Type of study & Population & Findings \\
\hline Fujihara et al. [51] & Observational & $\begin{array}{l}\text { Healthy middle-age Japanese } \\
\text { men }\end{array}$ & $\begin{array}{l}\text { Low FT and high SHBG plasma levels are } \\
\text { associated with a higher FIB-4 index }\end{array}$ \\
\hline Hazlehurst et al. [64] & Trial & $\begin{array}{l}\text { Healthy young male treated with } \\
\text { finasteride/dutasteride }\end{array}$ & $\begin{array}{l}\text { Increased metabolic risk and intrahepatic lipid } \\
\text { accumulation on MRS in patients treated with } \\
\text { dutasteride }\end{array}$ \\
\hline Gild et al. [69] & Observational & $\begin{array}{l}\text { Adult men with PCa undergoing } \\
\text { ADT }\end{array}$ & $\begin{array}{l}\text { Increased risk of NAFLD and any liver disease in } \\
\text { treated patients }\end{array}$ \\
\hline Sawazaki et al. [70] & Observational & Men with PCa undergoing ADT & $\begin{array}{l}\text { Increased intrahepatic fatty deposition on } \\
\text { abdominal CT }\end{array}$ \\
\hline
\end{tabular}

ADT: androgen-deprivation therapy; ALT: alanine aminotransferase; cFT: calculated free testosterone; cFE2: calculated free estradiol; CT: computed tomography; MRS: magnetic resonance spectroscopy; PCa: prostate cancer

\section{Sex hormones, hormonal therapy and NAFLD: evidence from clinical practice}

The above mentioned data suggest a plausible involvement of sex hormones and sex hormones abnormalities in the pathophysiology of NAFLD. From a clinical point of view, these observations have raised several questions about the possible effects of hormonal treatments and drugs modulating the hormonal pathways in affecting the risk of NAFLD.

The anti-androgen therapy is a cornerstone in the management of metastatic prostate cancer [67], but it negatively affects metabolic homeostasis favoring the development of obesity and metabolic diseases [68]. In fact, in patients undergoing ADT for prostate cancer, hormonal treatment is associated with the development of MetS and T2DM and, as a consequence of weight gain and/or the development of MetS, ADT has been recently recognized as a risk factor for the development of NAFLD. Epidemiological studies demonstrated that the diagnosis of NAFLD and even cirrhosis was more common after ADT in patients without known liver disease at baseline, with an apparent dose-response relationship [69]. In addition, in patients with diagnosed NAFLD, 6 months of ADT was associated with the progression of hepatic steatosis on abdominal CT [70].

The relationship between androgens, prostate and NAFLD could be more intriguing considering some epidemiological studies proposing a relationship between prostate cancer and NAFLD: in a large epidemiological study involving more than 10 million subjects, high fatty liver index and hepatic steatosis index were independently associated with the development of prostate cancer [71]. However, there are conflicting evidence showing that NAFLD is protective for prostate cancer recurrency after radical prostatectomy [72].

Testosterone supplementation has been demonstrated to revert unfavorable metabolic profile in subjects with obesity and MetS and low testosterone plasma levels. In addition, testosterone replacement therapy in subjects with T2DM promotes the amelioration of all metabolic parameters [73]. Testosterone influences metabolic homeostasis, by increasing lean while reducing fat mass, with consequent improvement of glucose sensitivity and normalization of triglycerides accumulation from adipose depots [74]. To this regard, the role of testosterone in the development of prostate cancer has been recently questioned, with accumulating evidence providing that testosterone treatment seems to prevent metabolic abnormalities without affecting neoplasm prognosis after a definitive therapy [75]. These results may be partially due also to a plausible anti-inflammatory effects proposed for testosterone [76], with several epidemiological studies showing an inverse correlation between testosterone plasma levels and circulating pro-inflammatory mediators such as high sensitivity- $C$ reactive protein, tumor necrosis factor- $\alpha$, macrophage inflammatory protein- $1 \alpha$, macrophage inflammatory protein-1 $\beta$, and interleukin-6 [77]. However, this is in contrast with a recent study demonstrating a pro-inflammatory and pro-fibrotic effect of testosterone: in animal models, androgen supplementation was associated with an increased inflammatory response in the liver modulating the activity of NLR family pyrin domain containing 3 (NLRP3) inflammasome [78], a biological pathway which seems directly involved in hepatic damage $[79,80]$.

As reported above, the inhibition of the $5 \alpha \mathrm{R}$ seems to influence hepatic metabolism, increasing the risk of NAFLD development. The failure to convert testosterone to DHT could favor a "functional hypogonadal 
state" promoting metabolic abnormalities progressing to liver steatosis and then steatohepatitis (Figure 2). In this sense, some authors hypothesized a risk of NAFLD during treatment with finasteride or dutasteride [81]. However, evidence is not so strong yet to limit their use in clinical practice.

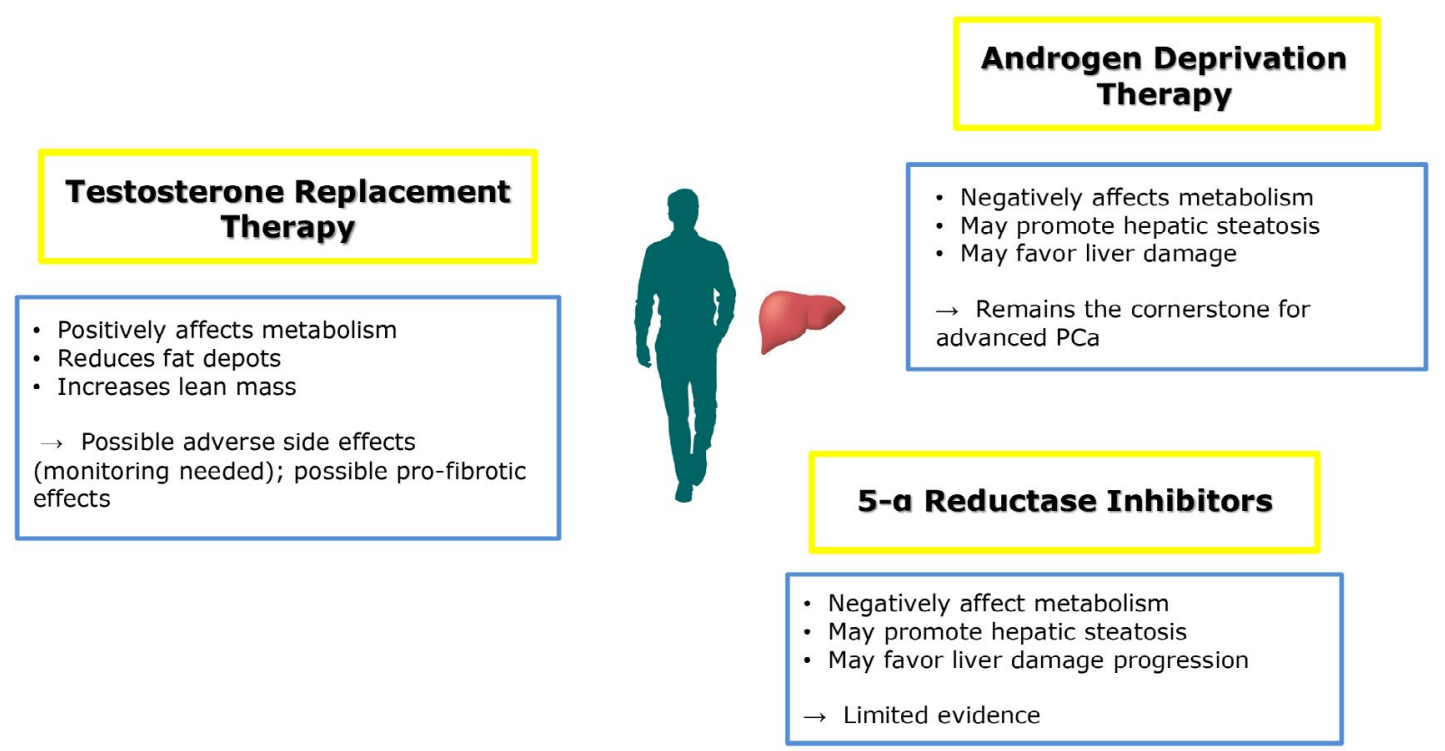

Figure 2. Hormonal therapy in men and NAFLD risk. PCa: prostate cancer

\section{Conclusions}

There is an intricate relationship between metabolic impairment and sex steroids abnormalities, and sex hormones may independently affect metabolic homeostasis. Androgens and estrogens directly mediate liver function through receptor activation, representing a plausible mechanism by which sex steroids could promote the development of NAFLD in patients with obesity and metabolic syndrome. However, different gender-related effects of sex steroids are observed, with low testosterone levels affecting liver function in men but not in young women, where hyperandrogenism has been associated with NAFLD. The complex effects of sex hormones are also demonstrated by the dual effects of androgens during aging in the female, with high androgens levels promoting the development of NAFLD in pre-menopausal period and but not in menopausal women, when low testosterone levels represent a risk factor for NAFLD. Further studies are needed to better understand the signaling pathways of androgens and estrogens in the hepatocytes and the possible therapeutic implications.

\section{Abbreviations}

$5 \alpha \mathrm{R} 1: 5 \alpha$-reductase type 1

ADT: androgen-deprivation therapy

AR: androgen receptor

DHT : dihydrotestosterone

ER: estrogen receptor

HCC: hepatocellular arcinoma

MetS: metabolic syndrome

NAFLD: non alcoholic fatty liver disease

PCOS: polycystic ovary syndrome

T2DM: type 2 diabetes mellitus 


\section{Declarations}

Author contributions

ADV and MR contributed conception of the study; ADV, LR and MR wrote sections of the manuscript. All authors contributed to manuscript revision, read, and approved the submitted version.

\section{Conflicts of interest}

The authors declare that they have no conflicts of interest.

\section{Ethical approval}

Not applicable.

\section{Consent to participate}

Not applicable.

\section{Consent to publication}

Not applicable.

\section{Availability of data and materials}

Not applicable.

\section{Funding}

Not applicable.

\section{Copyright}

(c) The Author(s) 2021.

\section{References}

1. Eslam M, Newsome PN, Sarin SK, Anstee QM, Targher G, Romero-Gomez M, et al. A new definition for metabolic dysfunction-associated fatty liver disease: an international expert consensus statement. J Hepatol. 2020;73:202-9.

2. Ballestri S, Zona S, Targher G, Romagnoli D, Baldelli E, Nascimbeni F, et al. Nonalcoholic fatty liver disease is associated with an almost twofold increased risk of incident type 2 diabetes and metabolic syndrome. Evidence from a systematic review and meta-analysis. J Gastroenterol Hepatol. 2016;31:936-44.

3. Ampuero J, Aller R, Gallego-Durán R, Crespo J, Calleja JL, García-Monzón C, et al; HEPAmet Registry. Significant fibrosis predicts new-onset diabetes mellitus and arterial hypertension in patients with NASH. J Hepatol. 2020;73:17-25.

4. Kahl S, Gancheva S, Straßburger K, Herder C, Machann J, Katsuyama H, et al. Empagliflozin effectively lowers liver fat content in well-controlled type 2 diabetes: a randomized, double-blind, phase 4, placebocontrolled trial. Diabetes Care. 2020;43:298-305.

5. Hartman ML, Sanyal AJ, Loomba R, Wilson JM, Nikooienejad A, Bray R, et al. Effects of novel dual GIP and GLP-1 receptor agonist tirzepatide on biomarkers of nonalcoholic steatohepatitis in patients with type 2 diabetes. Diabetes Care. 2020;43:1352-5.

6. European Association for the Study of the Liver (EASL); European Association for the Study of Diabetes (EASD); European Association for the Study of Obesity (EASO). EASL-EASD-EASO Clinical Practice Guidelines for the management of non-alcoholic fatty liver disease. J Hepatol. 2016;64:1388-402.

7. Lassailly G, Caiazzo R, Buob D, Pigeyre M, Verkindt H, Labreuche J, et al. Bariatric surgery reduces features of nonalcoholic steatohepatitis in morbidly obese patients. Gastroenterology. 2015;149:379-88. 
8. Di Lorenzo N, Antoniou SA, Batterham RL, Busetto L, Godoroja D, Lossa A, et al. Clinical practice guidelines of the European Association for Endoscopic Surgery (EAES) on bariatric surgery: update 2020 endorsed by IFSO-EC, EASO and ESPCOP. Surg Endosc. 2020;34:2332-58.

9. Kirlangic OF, Yilmaz-Oral D, Kaya-Sezginer E, Toktanis G, Tezgelen AS, Sen E, et al. The effects of androgens on cardiometabolic syndrome: current therapeutic concepts. Sex Med. 2020;8:132-55.

10. Parolin M, Beghetto M, Fallo F, Di Vincenzo A, Vettor R, Mioni R, et al. Early atherosclerosis in polycystic ovary syndrome. a systematic review, meta-analysis and meta-regression. J Endocr Soc. 2020; 4 Suppl 1:SAT-LB98.

11. Rosso C, Kazankov K, Younes R, Esmaili S, Marietti M, Sacco M, et al. Crosstalk between adipose tissue insulin resistance and liver macrophages in non-alcoholic fatty liver disease. J Hepatol. 2019;71:1012-21.

12. Younossi Z, Anstee QM, Marietti M, Hardy T, Henry L, Eslam M, et al. Global burden of NAFLD and NASH: trends, predictions, risk factors and prevention. Nat Rev Gastroenterol Hepatol. 2018;15:11-20.

13. Targher G, Day CP, Bonora E. Risk of cardiovascular disease in patients with nonalcoholic fatty liver disease. N Engl J Med. 2010;363:1341-50.

14. Lonardo A, Ballestri S, Chow PKH, Suzuki A. Sex disparity in hepatocellular carcinoma owing to NAFLD and non-NAFLD etiology: epidemiological findings and pathobiological mechanisms. Hepatoma Res. 2020;6:83.

15. Yeh SH, Chen PJ. Gender disparity of hepatocellular carcinoma: the roles of sex hormones. Oncology. 2010;78 Suppl 1:172-9.

16. Liu WH, Yeh SH, Lu CC, Yu SL, Chen HY, Lin CY, et al. MicroRNA-18a prevents estrogen receptoralpha expression, promoting proliferation of hepatocellular carcinoma cells. Gastroenterology. 2009; 136:683-693.

17. Chalasani N, Younossi Z, Lavine JE, Charlton M, Cusi K, Rinella M, et al. The diagnosis and management of nonalcoholic fatty liver disease: practice guidance from the American Association for the Study of Liver Diseases. Hepatology. 2018;67:328-57.

18. Sarkar M, Suzuki A. Reproductive health and nonalcoholic fatty liver disease in women: considerations across the reproductive lifespan. Clin Liver Dis (Hoboken). 2020;15:219-22.

19. Hamaguchi M, Kojima T, Ohbora A, Takeda N, Fukui M, Kato T. Aging is a risk factor of nonalcoholic fatty liver disease in premenopausal women. World J Gastroenterol. 2012;18:237-43.

20. Wang $\mathrm{Z}, \mathrm{Xu} \mathrm{M}, \mathrm{Hu} \mathrm{Z}$, Shrestha UK. Prevalence of nonalcoholic fatty liver disease and its metabolic risk factors in women of different ages and body mass index. Menopause. 2015;22:667-73.

21. Salvoza NC, Giraudi PJ, Tiribelli C, Rosso N. Sex differences in non-alcoholic fatty liver disease: hints for future management of the disease. Explor Med. 2020;1:51-74.

22. Non-alcoholic Fatty Liver Disease Study Group; Lonardo A, Bellentani S, Argo CK, Ballestri S, Byrne CD, Caldwell SH, et al. Epidemiological modifiers of non-alcoholic fatty liver disease: focus on high-risk groups. Dig Liver Dis. 2015;47:997-1006.

23. Lonardo A, Nascimbeni F, Ballestri S, Fairweather D, Win S, Than TA, et al. Sex differences in nonalcoholic fatty liver disease: state of the art and identification of research gaps. Hepatology. 2019;70:1457-69.

24. Mauvais-Jarvis F, Bairey Merz N, Barnes PJ, Brinton RD, Carrero JJ, DeMeo DL, et al. Sex and gender: modifiers of health, disease, and medicine. Lancet. 2020;396:565-82.

25. Frühbeck G, Busetto L, Dicker D, Yumuk V, Goossens GH, Hebebrand J, et al. The ABCD of obesity: an EASO position statement on a diagnostic term with clinical and scientific implications. Obes Facts. 2019;12:131-6.

26. Rotterdam ESHRE/ASRM-Sponsored PCOS consensus workshop group. Revised 2003 consensus on diagnostic criteria and long-term health risks related to polycystic ovary syndrome (PCOS). Hum Reprod. 2004;19:41-7. 
27. Hales CM, Carroll MD, Fryar CD, Ogden CL [Internet]. Prevalence of obesity and severe obesity among adults: United States, 2017-2018. National Center for Health Statistics; NCHS Data Brief No. 360. [2020, February]. Available from: https://www.cdc.gov/nchs/products/databriefs/db360.htm

28. Garawi F, Devries K, Thorogood N, Uauy R. Global differences between women and men in the prevalence of obesity: is there an association with gender inequality? Eur J Clin Nutr. 2014;68:1101-6.

29. Singh R, Artaza JN, Taylor WE, Braga M, Yuan X, Gonzalez-Cadavid NF, et al. Testosterone inhibits adipogenic differentiation in 3T3-L1 cells: nuclear translocation of androgen receptor complex with beta-catenin and T-cell factor 4 may bypass canonical Wnt signaling to down-regulate adipogenic transcription factors. Endocrinology. 2006;147:141-54.

30. Stellato RK, Feldman HA, Hamdy O, Horton ES, McKinlay JB. Testosterone, sex hormone-binding globulin, and the development of type 2 diabetes in middle-aged men: prospective results from the Massachusetts male aging study. Diabetes Care. 2000;23:490-4.

31. Völzke H, Aumann N, Krebs A, Nauck M, Steveling A, Lerch MM, et al. Hepatic steatosis is associated with low serum testosterone and high serum DHEAS levels in men. Int J Androl. 2010;33:45-53.

32. Van de Velde F, Bekaert M, Hoorens A, Geerts A, T'Sjoen G, Fiers T, et al. Histologically proven hepatic steatosis associates with lower testosterone levels in men with obesity. Asian J Androl. 2020;22:252-7.

33. Sarkar M, Yates K, Suzuki A, Lavine J, Gill R, Ziegler T, et al. Low testosterone is associated with nonalcoholic steatohepatitis and fibrosis severity in men. Clin Gastroenterol Hepatol. 2021;19:400-2.

34. Yim JY, Kim J, Kim D, Ahmed A. Serum testosterone and non-alcoholic fatty liver disease in men and women in the US. Liver Int. 2018;38:2051-9.

35. Jaruvongvanich V, Sanguankeo A, Riangwiwat T, Upala S. Testosterone, sex hormone-binding globulin and nonalcoholic fatty liver disease: a systematic review and meta-analysis. Ann Hepatol. 2017;16:382-94.

36. Kumarendran B, O’Reilly MW, Manolopoulos KN, Toulis KA, Gokhale KM, Sitch AJ, et al. Polycystic ovary syndrome, androgen excess, and the risk of nonalcoholic fatty liver disease in women: a longitudinal study based on a United Kingdom primary care database. PLoS Med. 2018;15:e1002542.

37. Sarkar M, Terrault N, Chan W, Cedars MI, Huddleston HG, Duwaerts CC, et al. Polycystic ovary syndrome (PCOS) is associated with NASH severity and advanced fibrosis. Liver Int. 2020;40:355-9.

38. Stanczyk FZ. Androgen measurements. In: Azziz R., Nestler J.E., Dewailly D., editors. Androgen excess disorders in women. Contemporary endocrinology. New York: Humana Press.2006. pp. 63-72.

39. Christ-Crain M, Meier C, Huber P, Zimmerli L, Trummler M, Müller B. Comparison of different methods for the measurement of serum testosterone in the aging male. Swiss Med Wkly. 2004;134:193-7.

40. Janse F, Eijkemans MJ, Goverde AJ, Lentjes EG, Hoek A, Lambalk CB, et al. Assessment of androgen concentration in women: liquid chromatography-tandem mass spectrometry and extraction RIA show comparable results. Eur J Endocrinol. 2011;165:925-33.

41. Bloomer SA, Wellen KE, Henderson GC. Sexual dimorphism in the hepatic protein response to a moderate trans fat diet in senescence-accelerated mice. Lipids Health Dis. 2017;16:243.

42. Yang JD, Abdelmalek MF, Pang H, Guy CD, Smith AD, Diehl AM, et al. Gender and menopause impact severity of fibrosis among patients with nonalcoholic steatohepatitis. Hepatology. 2014;59:1406-14.

43. Palmisano BT, Zhu L, Stafford JM. Role of estrogens in the regulation of liver lipid metabolism. Adv Exp Med Biol. 2017;1043:227-56.

44. Birzniece V. Hepatic actions of androgens in the regulation of metabolism. Curr Opin Endocrinol Diabetes Obes. 2018;25:201-8.

45. Kur P, Kolasa-Wołosiuk A, Misiakiewicz-Has K, Wiszniewska B. Sex hormone-dependent physiology and diseases of liver. Int J Environ Res Public Health. 2020;17:2620. 
46. Ballestri S, Nascimbeni F, Baldelli E, Marrazzo A, Romagnoli D, Lonardo A. NAFLD as a sexual dimorphic disease: role of gender and reproductive status in the development and progression of nonalcoholic fatty liver disease and inherent cardiovascular risk. Adv Ther. 2017;34:1291-326.

47. Chikada H, Ida K, Ando E, Inagaki Y, Sakamoto A, Kamiya A. Establishment and analysis of a mouse model that regulates sex-related differences in liver drug metabolism. Lab Invest. 2018;98:1500-11.

48. Malespin M, Nassri A. Endocrine diseases and the liver: an update. Clin Liver Dis. 2019 May;23:233-46.

49. Grossmann M, Wierman ME, Angus P, Handelsman DJ. Reproductive endocrinology of nonalcoholic fatty liver disease. Endocr Rev. 2019;40:417-46.

50. Sarkar M, Wellons M, Cedars MI, VanWagner L, Gunderson EP, Ajmera V, et al. Testosterone levels in premenopausal women are associated with nonalcoholic fatty liver disease in midlife. Am J Gastroenterol. 2017;112:755-62.

51. Fujihara Y, Hamanoue N, Yano H, Tanabe M, Akehi Y, Nomiyama T, et al. High sex hormone-binding globulin concentration is a risk factor for high fibrosis-4 index in middle-aged Japanese men. Endocr J. 2019;66:637-45.

52. Shen M, Shi H. Sex hormones and their receptors regulate liver energy homeostasis. Int J Endocrinol. 2015;2015:294278.

53. Ma WL, Lai HC, Yeh S, Cai X, Chang C. Androgen receptor roles in hepatocellular carcinoma, fatty liver, cirrhosis and hepatitis. Endocr Relat Cancer. 2014;21:R165-82.

54. Acosta-Lopez S, Diaz-Bethencourt D, Concepción-Massip T, Martin-Fernandez de Basoa MC, PlataBello A, Gonzalez-Rodriguez A, et al. The androgen receptor expression and its activity have different relationships with prognosis in hepatocellular carcinoma. Sci Rep. 2020;10:22046.

55. Eagon PK, Elm MS, Epley MJ, Shinozuka H, Rao KN. Sex steroid metabolism and receptor status in hepatic hyperplasia and cancer in rats. Gastroenterology. 1996;110:1199-207.

56. Li H, Li Y, Lu JW, Huo X, Gong Z. Liver-specific androgen receptor knockout attenuates early liver tumor development in zebrafish. Sci Rep. 2019;9:10645.

57. Meda C, Barone M, Mitro N, Lolli F, Pedretti S, Caruso D, et al. Hepatic ER $\alpha$ accounts for sex differences in the ability to cope with an excess of dietary lipids. Mol Metab. 2020;32:97-108.

58. Zhu L, Martinez MN, Emfinger CH, Palmisano BT, Stafford JM. Estrogen signaling prevents dietinduced hepatic insulin resistance in male mice with obesity. Am J Physiol Endocrinol Metab. 2014;306:E1188-97.

59. Cooke PS, Heine PA, Taylor JA, Lubahn DB. The role of estrogen and estrogen receptor-alpha in male adipose tissue. Mol Cell Endocrinol. 2001;178:147-54.

60. Dowman JK, Hopkins LJ, Reynolds GM, Armstrong MJ, Nasiri M, Nikolaou N, et al. Loss of $5 \alpha$-reductase type 1 accelerates the development of hepatic steatosis but protects against hepatocellular carcinoma in male mice. Endocrinology. 2013;154:4536-47.

61. Bau drand R, Domínguez JM, Carvajal CA, Riquelme A, Campino C, Macchiavello S, et al. Overexpression of hepatic $5 \alpha$-reductase and $11 \beta$-hydroxysteroid dehydrogenase type 1 in visceral adipose tissue is associated with hyperinsulinemia in morbidly obese patients. Metabolism. 2011;60:1775-80.

62. Livingstone DE, Barat P, Di Rollo EM, Rees GA, Weldin BA, Rog-Zielinska EA, et al. $5 \alpha$-Reductase type 1 deficiency or inhibition predisposes to insulin resistance, hepatic steatosis, and liver fibrosis in rodents. Diabetes. 2015;64:447-58.

63. Upreti R, Hughes KA, Livingstone DE, Gray CD, Minns FC, Macfarlane DP, et al. $5 \alpha$-reductase type 1 modulates insulin sensitivity in men. J Clin Endocrinol Metab. 2014;99:E1397-406.

64. Hazlehurst JM, Oprescu AI, Nikolaou N, Di Guida R, Grinbergs AE, Davies NP, et al. Dual-5 $\alpha$-reductase inhibition promotes hepatic lipid accumulation in man. J Clin Endocrinol Metab. 2016;101:103-13. 
65. Nasiri M, Nikolaou N, Parajes S, Krone NP, Valsamakis G, Mastorakos G, et al. $5 \alpha$-reductase type 2 regulates glucocorticoid action and metabolic phenotype in human hepatocytes. Endocrinology. 2015;156:2863-71.

66. Nikolaou N, Gathercole LL, Marchand L, Althari S, Dempster NJ, Green CJ, et al. AKR1D1 is a novel regulator of metabolic phenotype in human hepatocytes and is dysregulated in non-alcoholic fatty liver disease. Metabolism. 2019;99:67-80.

67. Heidenreich A, Bastian PJ, Bellmunt J, Bolla M, Joniau S, van der Kwast T, et al. EAU guidelines on prostate cancer. Part II: Treatment of advanced, relapsing, and castration-resistant prostate cancer. Eur Urol. 2014;65:467-79.

68. Keating NL, O'Malley AJ, Freedland SJ, Smith MR. Diabetes and cardiovascular disease during androgen deprivation therapy: observational study of veterans with prostate cancer. J Natl Cancer Inst. 2010;102:39-46.

69. Gild P, Cole AP, Krasnova A, Dickerman BA, von Landenberg N, Sun M, et al. Liver disease in men undergoing androgen deprivation therapy for prostate cancer. J Urol. 2018;200:573-81.

70. Sawazaki H, Kitamura Y, Yagi K, Arai Y. Impact of androgen deprivation therapy on non-alcoholic fatty liver disease in patients with prostate cancer: a CT evaluation. Urol Int. 2020;104:425-30.

71. Choi YJ, Lee DH, Han KD, Yoon H, Shin CM, Park YS, et al. Is nonalcoholic fatty liver disease associated with the development of prostate cancer? A nationwide study with 10,516,985 Korean men. PLoS One. 2018;13:e0201308.

72. Choi WM, Lee JH, Yoon JH, Kwak C, Lee YJ, Cho YY, et al. Nonalcoholic fatty liver disease is a negative risk factor for prostate cancer recurrence. Endocr Relat Cancer. 2014;21:343-53.

73. Heufelder AE, Saad F, Bunck MC, Gooren L. Fifty-two-week treatment with diet and exercise plus transdermal testosterone reverses the metabolic syndrome and improves glycemic control in men with newly diagnosed type 2 diabetes and subnormal plasma testosterone. J Androl. 2009;30:726-33.

74. Maneschi E, Morelli A, Filippi S, Cellai I, Comeglio P, Mazzanti B, et al. Testosterone treatment improves metabolic syndrome-induced adipose tissue derangements. J Endocrinol. 2012;215:347-62.

75. Kardoust Parizi M, Abufaraj M, Fajkovic H, Kimura S, Iwata T, D’Andrea D, et al. Oncological safety of testosterone replacement therapy in prostate cancer survivors after definitive local therapy: a systematic literature review and meta-analysis. Urol Oncol. 2019;37:637-46.

76. Dhindsa S, Ghanim H, Batra M, Kuhadiya ND, Abuaysheh S, Sandhu S, et al. Insulin resistance and inflammation in hypogonadotropic hypogonadism and their reduction after testosterone replacement in men with type 2 diabetes. Diabetes care. 2016;39:82-91.

77. Bobjer J, Katrinaki M, Tsatsanis C, Lundberg Giwercman Y, Giwercman A. Negative association between testosterone concentration and inflammatory markers in young men: a nested cross-sectional study. PLoS One. 2013;8:e61466.

78. Ma X, Zhou Y, Qiao B, Jiang S, Shen Q, Han Y, et al. Androgen aggravates liver fibrosis by activation of NLRP3 inflammasome in CCl4-induced liver injury mouse model. Am J Physiol Endocrinol Metab. 2020;318:E817-29.

79. Mridha AR, Wree A, Robertson AAB, Yeh MM, Johnson CD, Van Rooyen DM, et al. NLRP3 inflammasome blockade reduces liver inflammation and fibrosis in experimental NASH in mice. J Hepatol. 2017;66:1037-46.

80. Rossato M, Di Vincenzo A, Pagano C, El Hadi H, Vettor R. The P2X7 receptor and NLRP3 axis in nonalcoholic fatty liver disease: a brief review. Cells. 2020;9:1047.

81. Traish AM. Health risks associated with long-term finasteride and dutasteride use: it's time to sound the alarm. World J Mens Health. 2020;38:323-37. 